of dissipation, cannot he relieved by any one drug or discovery of this new disease and its successful treatcombination of drugs alome, but by building up the ment may be judged fairly and honestly by the whole body by special diet, baths, exercise, electricity pliysicians.

and good hygienic surroundings.

The science of medicine has commenced a new war

In my hands a combination of drugs has proved against an old but recently discovered disease. Have most beneficial. Fach and every case must have effectual and successful remedies been found for this special treatment according to the symptoms disease? To this we answer, yes. When the details manifest.

of the methods and remedies now used are perfected

No doubt chloride of gold possesses wonderful by further experience, and their capabilities and alternative properties, and when properly and syste- limitations more fully tested by the medical promatically given in combination with strychnia, atro- fession.

phia, cocoa, quinine, sulphonal, and codea, they have The public should not expect them to prove infala tendency to change the habits of the system and lible. The best that can be expected in any disease remove the diseased condition of the nerve centers and allow nature to return to a normal condition.

These powerful drugs, when given for a long time, so profoundly influence and build up the nervous system, that the inebriate feels strong and well, and gradually acquires as much repugnance for stimulants as he before had an appetite for them. The treatment breaks or removes the cause of the disease, and the inebriate starts in a new career of life. Of course he may relapse, as he may from any other nervous disease. Anything that tends to exhaust the brain, or lower the vital forces predisposes fo a return of the disease.

The individual should live a life free from excitement, annoyance and worry, eat wholesome and substantial food and be constantly under the observation of a physician. Physicians who are familiar with the modern treatment of inebriety do not condemn it: but they rightfully refuse to endorse nostrums of which they know nothing. The general practitioner has not the time to devote to the treatment of these cases. He might as well attempt to treat all his cases of insanity.

Specialists have explored the grounds, investigated the disease and formulated the treatment, and are therefore more competent to handle such cases successfully. Nor is it advisable for the patient to treat himself. Most drugs that are of any value in this disease would prove dangerous in his hands. Besides, the most of the treatment must be given hypodermically, which an unskilled person cannot use.

My reason for dwelling upon the neurological and pathological aspect of this disease, is to call the attention of those outside of the medical profession to the great advancements that have been made in this special department of the healing art. The world is too apt to look with disfavor upon any new discovery that is invisible and incomprehensive to the common mind.

They grow wild over the graphophone, the telephone or electric car, but fail to realize the subtle and invisible agents that science is using to cure man. In conclusion, we may then state with perfect confidence, that inebriety is a disease and not a habit, and being a disease is therefore curable; and in order to intelligently treat it, we must study the nature and character of the disease as it manifests itself in different individuals. We must approach the subject from the physical, and not the normal side of the case. We must discard any preconceived notions and theories not based upon facts. The success of the new treatment has opened up a promising future to all who may investigate the subject.

Now that the smoke of battle following the conflict of the able article in the Review (on both sides of this question) is clearing away, we trust that the

is that it will cure the majority of all the patients to whom it is properly administered, and this is just what this modern treatment has done in dipsomania. The deliverance of humanity from this terrible disease will mark a new epoch in the science of medicine.

Facts are the basis of an infinite wisdom that never errs. The discovery of every new truth in medical science marks its advancement over past ages. New discoveries spring up with such rapidity that in the busy routine of professional life we have scarcely time to sift, weigh, and analyze their value for good or evil. By the selfishness of our natures, we are more prone to condemn, criticise, than to praise.

President Garfield once remarked that he was always struck with awe when standing near the ocean and seeing the waves lashed into fury and tossed into spray. Its grandeur would move the soul of the dullest man. But it was not from these billows, but the calm level of the sea, from which all heights and depths, lengths and widths, are measured. And so in the conflicts of science like the waves of the ocean. One follows the other, and after a moment's existence each one in turn is overwhelmed by the one that follows, and both are merged into the past. But human thought differs from the waves of the ocean in this: that we advance in wisdom and knowledge, and that an occasional wave is thrown so far out that it will never recede, so that the eyes of the whole world can behold the progress that has been made to save and prolong human life.

The medical profession is progressing, not only in the United States, but in England, Germany, France, Italy, Spain, Belgium, and the islands of the seas. This century has had its Virchow, Pasteur, Lister, Esmarch, Tait, Billroth, Paget, Koch, Simms, Morton, McDowell, Gross, Pancoast, and Agnew.

\section{DIAGNOSIS OF PNEUMONIA.}

Read before Chicago Medical Society, February 15, 1892. BY JOSEPH M. PATTON, M.D.,

PROFESSOR OF INTERAI MEDICINE IN THE CHICAGO POLYCLINIC.

There is nothing especially new to be said on the subject of the diagnosis of pneumonia. The symptoms, both subjective and objective, upon which the diagnosis of a typical case of the disease is to be based are so familiar to you all that it would be superfluous to enumerate them, and yet the difficulties of making a correct diagnosis, which are sometimes present, remind us that the clear clinical picture as depicted in our text-books is at times widely departed from in clinical fact.

Let us make a brief comparison of relative diagnostic merits of the symptoms which present.

Some diagnostic importance is to be attached to 
the facies of the disorder. The anxious countenance, combined with the pneumonic spot over the malar prominence, the mahogany color which this spot may assume, and which may be an early objective sign, are at times characteristic. There is also a peculiar heavy, sweetish odor to the skin and expectoration, which to me is, at times, quite diagnostic.

The chill.-The diagnostic importance of the chill lies in its being the initial symptom; in its violence, and in its not being repeated, it is more active than in any other disease except intermittent fever and septicamia. Pri contra 25 per cent. of cases do not exhibit the chill, and in senile life 60 per cent. may omit, or at least exhibit it only to a slight degree; a slight protracted chill, perhaps pain, great prostration, with fever, often constituting the first evidence of acute senile preumonia. In children the chill is often absent, its place being taken by gastric disturbances and nervous manifestations.

Temperature.-This is of importance in that it rises suddenly, and in two or three hours attains as great a height as it may during the disease. The daily oscillation of from $\frac{1}{2}-2^{\circ}$ may be of service in distinguishing from the gradual rise of typhoid, its rapid declination to the normal or below at the period of crisis may become diagnostic in cases not seen earlier.

The Respiration.-Is diagnostically important in its great rapidity, its independence of the pulse rate, and of the amount of lung tissue involved. It is also not in accordance with the pain or temperature. Its panting character is peculiar to pneumonia. Speech is short and jerky, interrupted, as expressed by Niemeyer, contraction of the levatores alæ nasi cause dilatation of the alse nasi, which is peculiarly noticeable in children. The difference between the pulse and respiration in children is not so marked as in adults.

Dyspucea.-Is of no diagnostic importance. It may or may not be present. Indeed, its absence, with a rapid respiratory rate, is diagnostic. When present it is panting in character and does not relate to the amount of lung tissue involved. It is apt to be greatest where there is grave nervous disturbance in secondary and complicated pneumonias and in children. In old age it is rarely present, even with a breathing rate of 60 or 70 ; here its absence is important.

Prin.-Pain is present in 80 per cent. of the cases over the affected lung. Its diagnostic importance rests in the fact that it disappears in one or two days, provided that pleuro-pneumonia is not present. It is absent in central pneumonias, in pneumonia of the upper lobes or apex, and in senile pneumonia it is not severe, or is entirely absent.

( ough.-Cough is present in the great majority of cases except in old people. It is one of the earliest symptoms, hacking in character, and most persistent in children. The muscular effort required in coughing may cause great exhaustion.

The Expertoration. - The expectoration furnishes one of the characteristic evidences of the disease. It is at first frothy and light colored, later becomes viscid and tenacious, but never opaque (Loomis). It then becomes of the well known rusty hue or prune juice color, depending on the quantity of blood in it, or according to Jacksch, to dissolved hæmoglobin. It may be grass green in color, due to conversion of hamoglobin or hamatin into bilirubin, which in turn is oxidized into biliverdin. The stickiness of the sputum is characteristic, and when removed from the mouth in the folds of a cloth, upon separating the folds of cloth the sputum will stretch out into a thin film which is quite elastic. Chemically the sputum contains albumin, mucin, sometimes tyrosin and sugar. It contains more potash than catarrhal sputum and less soda, and no alkaline phosphates as compared with 12 per cent. in catarrhal sputum. Pneumonic sputum is acid in reaction, due, according to Verdeil, to excess of pneumic acid; according to Bamberger, to deficiency in alkaline phosphates. Microscopically the sputum contains, hesides the different elements derived from the products of consolidation, red and white blood cells and fat gramules. According to Walshe pus cells are not found in brickdust sputum. Various organisms may be present, of which the pneumococcus of Friedlinder has been regarded as to some extent diagnostic, but at present it is generally considered that various microörganisms may have some influence in producing the disease; at least the presence or absence of this diplococcus has not obtained any particular diagnostic significance. While a careful analysis of the above emphasized elements of the symptomatology may go, far towards making a diagnosis, it is to the physical signs that we look for positiveness.

The elassical physical signs of the disease are so familiar to you all, that it would be tiresome to enumerate them in order.

Let us note the comparative value of the different signs elicited by the different methods of examination in the different stages of the disease.

In.spertion.-During the first stage inspection will show nothing, for if there is slight loss of motion it may be due to pain. During the second stage there will be slight or considerable loss of motion depending on the amount of tissue involved, with a corresponding compensatory action of opposite side.

In double pneumonia of base of lungs the action of the diaphragm is diminished, and the respiration is costal in type. Increased action of the heart may be noticed. During the third stage, returning expansion of affected portions is observed.

Prlpation.-Except as a method of determining the expansion, palpation is of little value during the first stage, as the slight increase in vocal fremitus during that period is not diagnostic. It is important when obtained; it is most marked in consolidation of upper portion of lungs, may be absent in double pneumonia of lower portions in senile pneumonia, in moderate sized central consolidations, and in very extensive consolidation of one lung. Vocal fremitus in these instances may even be less marked than over the healthy lung. Pulsation may be felt over the inflamed tissue, attributed by some to arterial pulsation in the engorged lung, and by others to. transmission of the heart impulse; the latter is prob. ably the most frequent cause.

Perussion.-Like palpation, percussion is of practical value only during stages of consolidation, the slight dulness during first stage being readily confounded with slightly modified percussion pitch from other causes. Dulness is most readily obtained in apex pneumonias, and less so in central consolidations. It is more marked posteriorly than anteriorly. There is more resistance to the percussion stroke in pneumonia than in any other form of consolidation. A lower pitched note is obtained around the consolidated portion, and from the uninvolved lung tissue, 
this may be slightly tympanitic; with extensive consolidation a tympanitic note may be obtained over a large bronchus; a cracked pot sound may also be obtained from the same source.

With extensive basic consolidation the tension in the vesicles of the corresponding apex may be increased sufficiontly to give an amphoric quality to the percussion note.

luscultution.-The most diagnostic physical signs of pneumonic consolidation are furnished by auscultation. Auscultation of the voice during the first stage gives a higher pitched exaggeration of the voice, which is louder and more plainly heard. It has always seemed confusing to me to use the term "increased intensity" as applied to this condition, as compared to its use in relation to the low pitched percussion note. Exaggerated voice sounds nua be heard over a healthy lung where the tension of the tissue is increased and its elasticity lessened by the greater quantity of contained air, and also over tissue whose elasticity is lessened by vascular engorgement. In the former case the pitch is lower than in the latter.

During the second stage bronchophony is obtained, provided the bronchus is patent; according to Traube it may be heard during the first stage. Pectoriloquy may be heard where a bronchus is patent almost to the surface of the lung. (Egophony may also be heard. Voice sounds are modified by old age, rigidity of chest wall, emphysematous, asthmatic, and other modifications of the normal condition of the lungs.

Auscultation of the Respiration.-Respiratory auscultation is a most important means of diagnosing pneumonia. During the first stage the murmur is dry, harsher, slightly higher pitched, especially the expiration. During the latter portion of this stage the crepitant rîle is to be heard. Much has been said for and against the position assumed for this râle in the diagnosis of pneumonia. Loomis says they are usually pleuritic crepitations, and yet assumes for it a position relative to diagnosis not to be obtained by any pleuritic friction, and directly contrary to that opinion. The true crepitant râle comes only at the immediate end of inspiration in a burst of fine crepitations, producing a sensation to the ear similar to that on the eye produced by certain pyrotechnic displays which burst suddenly at a height into numerous and distinct bodies of light. There are pleuritic crepitations so closely resembling these as to be difficult, or perhaps impossible, of distinction; pneumonic crepitation is present in inflammations which do not reach the pleural surface, and when pleurisy will not explain their presence.

Pleuritic crepitation is of slightly longer duration, and does not produce so markedly the sensation of numerous crepitations instantaneously produced. While it may be difficult to always distinguish between these sounds, I do not think we are warranted in dismissing crepitation as a classical sign of the first stage of pneumonia. During the second stage hronchial breathing is the classical auscultatory sign, heard at first only during expiration; later on, both ruring expiration and inspiration, high pitched, hlowing or harsh in character. In basic or central inflammations it has the sensation of being produced at a distance, and is not so harsh as in pneumonia of the apex; it is generally obtained better behind than in front. In consolidation of upper or middle portion of lungs it is most marked at the superior angle of, or between, the scapulæ.
Laennec considered bronchial breathing due to better conduction by solid tissue; Skoda, to vibration of air in bronchi of condensed tissue in consonance with that in trachea, the solid walls around pent-up air in bronchi reflecting vibrations better.

During the second stage the heart-sounds may be heard at distant portions of chest with increased distinctness; râles from accompanying bronchitis (Skoda's consonating râles) may be very distinct.

During third stage, the gradual return of normal signs with subcrepitant râle or râles redux from liquefaction of products of consolidation form the only important signs.

Differential Dianmoxix. - The diseased conditions with which pneumonia may be confounded will depend on the stage at which the diagnosis is made.

During first stage from la grippe, cedema of the lungs, pulmonary congestion, acute pleurisy, and hypostatic congestion. In la grippe the chill (if there be one) is not so severe; the temperature may be as high, but the pulse is generally faster, though it may assume the peculiar independence of pneumonia. The whole face is flushed, and the eyes have a feverish instead of anxious look. The breathing is slower, and not panting. I have fornd it difficult in some cases, both of pneumonia and la grippe, to make a diagnosis until time for the development of physical signs had elapsed. Chronic œedema of lungs arises during the comrse of other affections explaining its presence.

Acute cdema arising from cerebral injuries, irritation of the par vagum, or after other acute diseases may be mistaken for pneumonia, but the dyspnoea is greater, the breathing more noisy, expectoration frothy and serous or blood-stained, if with congestion; the râles, which may be indistinguishable from pneumonic crepitation. will be accompanied by larger bubbling râles, usually through both lungs, while pneumonia is usually unilateral; there is also absence of chill and fever.

In low continued fevers crepitant râles may be neard at base of lungs, due to congestion; they are bilateral with no marked dyspnoea or dulness.

Acute pleurisy begins with varying chills, temperature below $101^{\circ}$, cough dry and irritating, pain severe, expectoration slight and mucus, face pale and anxious, pulse small and tense, breathing catching; may get friction sound limited to very small area, while in pneumonia face is flushed, breathing panting, pulse full, temperature high.

Hypostatic congestion occurs in enfeebled subjects, in bedridden people, in lowest portions of lungs. May disappear with change in posture, is accompanied by no fever, has copious watery or blondy expectoration.

Meningitis in children may also be mistaken for pneumonia with cerebral symptoms. In meningitis the temperature does not go so high, as a rule, its advent is more insidious, pulse lower, no dyspnca, face pale and distressed.

During second stage, pneumonia may be confounded with pulmonary infarction, pleurisy with effuion, acute phthisis, and lobular pneumonia.

Pulmonary infarction is connected with cardiac disease or pyæmia. There is no fever; sudden and intense dyspnoea is its main feature, the expectoration is red or black coagula of blood, there is limited circumscribed dullness surrounded by moist râles, there may be great pain, the breath has a peculiar odor. 
While in typical cases the differentiation of pleurisy with effusion from pneumonia is easy and familiar to all, there are cases where it may be mistaken.

In limited encapsulated effusions with connecting bands of tissue, there may be loss of motion, no distension of inter-costal spaces, dullness, increased fremitus, increased vocal resonance, high-pitched respiratory sounds, bronchial râles heard over the location of the fluid. These modifications may be entirely due to the thickened pleuræ and localized bronchitis, and are difficult to distinguish from basic pneumonia of insidious advent. In copious effusions there may be marked compression of lung without. protrusion of intercostal spaces, and bronchial breathing will be heard at the lower angle of left scapula. This may be mistaken for extensive pneumonia when there is not enough air in the lung to give any signs except over a large bronchus.

Per contre this latter condition may give such a paucity of physical signs that pleurisy is suspected. In senile pneumonia especially there may be consolidation of almost an entire lung which will not furnish one classical sign of the second stage except dullness. There is simply not enough air contained in the bronchi of the affected side to produce any vocal or respiratory sounds. Apex pneumonia may be confounded with acute phthisis. The characteristic symptoms and course of the affections are widely different, but the two conditions may be blended in such a manner that only the subsequent course of the disease will clear up doubt.

Lobar pneumonia in children is at times confusing. There is no chill, it is a secondary affection, is apt to be present in both lungs, and the physical signs are confined to circumscribed spots.

The third stage of pneumonia may be confounded with capillary bronchitis. The râles in the latter are heard all over one or both lungs, while in pneumonia they may be confined to a limited area in one lung.

In bronchitis the expectoration and temperature range are different. There is no dullness or morbid changes in voice sounds, breathing is labored, and there is more cyanosis. Senile pneumonia with typhoid symptoms, if not seen until late in its course, may be difficult or impossible to diagnose from typhoid fever; at an earlier period diagnosis is made from the relative sequence in the development of the physical signs of pneumonia and the symptoms of typhoid fever.

While in a case of pneumonia exhibiting the prominent symptoms in regular order there can be little or no difficulty in diagnosis, there are many cases where only careful consideration of all subjective and objective symptoms will prevent error. In some instances the subjective symptoms, which are very prominent in the beginning, will subside early in the case, and the patient who felt very ill when nothing physically wrong could be demonstrated, will now feel comparatively comfortable when everything wrong with the lungs is apparent.

The so-called typhoid pneumonia and bilious pneumonia are forms of the disease which have given rise to much discussion, both as to application of the terms and symptomatology. The term typhoid pneumonia has been rather indiscriminately applied to a variety of conditions with which a low form of pneumonia may be associated as a complication. The proper application would restrict it to that form of inflammation of the lungs which exhibits typhoid symptoms, and marked by rapid depression of vital power. A pneumonia complicating or following typhoid fever may be, but not necessarily so, a typhoid pneumonia.

Nervous symptoms are especially marked in typhoid pneumonia, more so than in any other, except apex inflammation in children.

Recovery is more protracted than in any other form of pneumonia. Bilions pneumonia is a form more common in the Southern States than in this latitude; it is characterized by gastric and hepatic derangements, and is considered by some to be of malarial origin. It is apparent that inflammation of the lungs occurring during the course of remittent fevers, or congestion or collapse of lung tissue during malarial fevers, might be erroneously classified as bilious pneumonia.

The terms typhoid and bilious as applied to pneumonic inflammation are not sufficiently accurate or expressive of a definite phase of the disease to merit a place in the nomenclature of pneumonia.

\section{SOCIETY PROCEEDINGS.}

\section{American Electro-Therapeutic Association.}

First 1 numal Heeting of the American Electro-Therapentic Asworiation, held in Philadelphia, September 24,25 and 26,1891 .

(Concluded from page 266.)

Ephraim Cutter, M.D., LL.D., President American Branch Society of Science, Letters and Art, of London; Corresponding Member Belgian and Italian Microseopical Societies; Physician-in-Chief Heartrest Sanatory, New York, read a paper on

THE GALVANO-CAUTERY; ITS USE IN REMOYAL OF PILES ANE GROWTHS.

Galvano-cautery is employed to remove growths without bleeding, and generally with complete and perfect cure. That is, malignant growths are not apt to recur on site of removal; they may occur elsewhere.

The tissues heal healthily, so that it is difficult at times to tell whence the growth has been removed.

Principles. - 1. Have a good battery; if a storage battery, test it well as to connections beforehand.

I use heavy conductors of pure silver; these are less bulky and more flexible than copper. Carbon and zinc plates variously connected so as to be portable, and not break; to have broad connections, with as few breaks as possible.

In the ordinary coupling with screw and socket there is not a typical connection. The connection of batteries should have broad surfaces coming in close contact, flatwise; in the ordinary screw coupling the contact is linear and tangential. Cam coupling. These I like, for they do not easily come apart. Screw couplings get loose almost invariably.

Cautery holder. Nine is very simple.

First, a tinsmith rolled up a piece of tin into a tapering tube 6 to 8 inches long, one-fourth inch in diameter at one end, and one-sixteenth inch at the other. Two such tubes were mounted on a glass window plate 4 inches long, one and a half at one end and one-half inch at the other end, by flanges of tin riveted through the glass, or held in place by India-rubber bands. The primitive timman's appliance I have would convey more current than the brass and nickelplated one made by the surgical instrument makers.

To use it: Simply run the ends of the conductors into 